\title{
(6) OPEN ACCESS \\ The effect of participatory women's groups on infant feeding and child health knowledge, behaviour and outcomes in rural Bangladesh: a controlled before-and-after study
}

\author{
Leila Younes, ${ }^{1}$ Tanja A J Houweling, ${ }^{1,2}$ Kishwar Azad, ${ }^{3}$ Abdul Kuddus, ${ }^{3}$ Sanjit Shaha, ${ }^{3}$ \\ Bedowra Haq, ${ }^{3}$ Tasmin Nahar, ${ }^{3}$ Munir Hossen, ${ }^{3}$ James Beard, ${ }^{1}$ Andrew Copas, ${ }^{4}$ \\ Audrey Prost, ${ }^{1}$ Anthony Costello, ${ }^{1}$ Edward Fottrell ${ }^{1}$
}

${ }^{1}$ UCL Institute for Global Health, University College London, London, UK

${ }^{2}$ Department of Public Health, ErasmusMC University Medical Center Rotterdam, Rotterdam, The Netherlands

${ }^{3}$ Perinatal Care Project (PCP), Diabetic Association of Bangladesh (BADAS), Dhaka, Bangladesh

${ }^{4}$ Department of Infection and Population Health, University College London, London, UK

\section{Correspondence to}

Dr Edward Fottrell, UCL Institute for Global Health, University College London, 30 Guilford Street, London WC1N 1EH, UK; e.fottrell@ucl.ac.uk

Received 28 April 2014 Revised 30 September 2014 Accepted 9 November 2014 Published Online First 3 December 2014
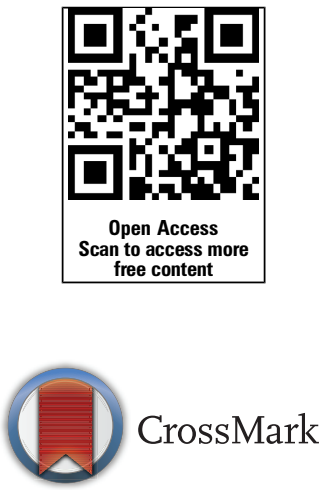

To cite: Younes $\mathrm{L}$, Houweling TAJ, Azad K, et al. J Epidemiol Community Health 2015:69:374-381.

\section{ABSTRACT}

Background Despite efforts to reduce under- 5 mortality rates worldwide, an estimated 6.6 million under-5 children die every year. Community mobilisation through participatory women's groups has been shown to improve maternal and newborn health in rural settings, but little is known about the potential of this approach to improve care and health in children after the newborn period.

Methods Following on from a cluster-randomised controlled trial to assess the effect of participatory women's groups on maternal and neonatal health outcomes in rural Bangladesh, 162 women's groups continued to meet between April 2010 and December 2011 to identify, prioritise and address issues that affect the health of children under 5 years. A controlled beforeand-after study design and difference-in-difference analysis was used to assess morbidity outcomes and changes in knowledge and practices related to child feeding, hygiene and care-seeking behaviour.

Findings Significant improvements were measured in mothers' knowledge of disease prevention and management, danger signs and hand washing at critical times. Significant increases were seen in exclusive breast feeding for at least 6 months (15.3\% (4.2\% to $26.5 \%)$ ), and mean duration of breast feeding (37.9 days (17.4 to 58.3)). Maternal reports of under-5 morbidities fell in intervention compared with control areas, including reports of fever $(-10.5 \%(-15.1 \%$ to $-6.0 \%))$ and acute respiratory infections $(-12.2 \%(-15.6 \%$ to $-8.8 \%)$ ). No differences were observed in dietary diversity scores or immunisation uptake.

Conclusions Community mobilisation through participatory women's groups can be successfully adapted to address health knowledge and practice in relation to child's health, leading to improvements in a number of child health indicators and behaviours.

\section{INTRODUCTION}

Despite efforts to reduce child mortality rates worldwide, an estimated 6.6 million children died before reaching their fifth birthday in $2012 .{ }^{1}$ Most of these deaths occurred in resource-poor settings.

Under-5 morbidity and mortality is determined by a mix of factors: the health knowledge of mothers; immunisation and oral rehydration therapy coverage; availability of maternal and child health services; availability of safe drinking water and basic sanitation; and the safety of the child's environment, among others. ${ }^{2} 3$ Interventions that aim to improve home care practices, health-seeking behaviour and improved coverage of essential interventions (including immunisation) can lead to significant reductions in under-5 mortality. ${ }^{34}$

Studies of knowledge and practice related to the health of under- $5 \mathrm{~s}$ have been conducted on mothers or women of reproductive age, and generally focus on single themes such as prevention and management of diarrhoea, acute respiratory infections (ARIs), knowledge and practices surrounding antenatal care, delivery, breast feeding or nutritional status of children. ${ }^{5-8}$ Many studies are either conducted in urban settings or at the facility level, with few studies investigating mothers' knowledge and practices on a range of integrated issues related to child health at the community level. ${ }^{78}$

In Bangladesh, around 53 children per 1000 live births die before their fifth birthday, mainly due to preventable causes including pneumonia, serious infections, birth asphyxia, drowning, preterm birth and undernutrition. ${ }^{9}$ This figure masks geographical and economic disparities in child mortality where the under-5 mortality rate is higher among children living in rural areas and in the poorest households. ${ }^{9}$ Strategies to tackle this in Bangladesh have largely focused on care and practices during pregnancy, childbirth and the neonatal period, mostly overlooking practices that may impact the health of children during the postneonatal period. ${ }^{11}{ }^{12}$ For older children, the Integrated Management of Childhood Illnesses (IMCI) has been shown to be an effective primary care case management strategy associated with positive outcomes, such as increases in rates of breast feeding. ${ }^{13}$ The success of IMCI programmes, however, depends mainly on the strength of the health system responsible for their implementation. ${ }^{14}$ In Bangladesh, health system constraints and capacity for scale-up and follow-up after training can hinder the expansion of high-quality IMCI strategies at the national level. ${ }^{15}$

Based on the documented impact of participatory women's groups on maternal and neonatal health outcomes in numerous settings, ${ }^{16-19}$ this formative study evaluates the potential of community mobilisation with women's groups as an approach to improve a range of health indicators and 
outcomes relating to the health of children under-5 in rural Bangladesh.

\section{METHODS}

Study setting and population

This study was implemented in 18 clusters in three districts in Bangladesh (figure 1) representing a total population of 532996 people. The three districts, Bogra, Faridpur and Moulavibazar, have an average under-5 mortality rate of $82 /$ 1000 live births compared with a national average of 53/1000 live births. ${ }^{9}$ The study clusters were selected during a previous cluster-randomised controlled trial to assess the impact of a community mobilisation women's group intervention on maternal and neonatal outcomes, summarised in figure 2 and described in detail elsewhere. ${ }^{20} 21$ In summary, the three districts were purposefully selected based on having active Diabetic Association of Bangladesh (BADAS) affiliated associations. Per district, two upazillas (subdistricts), and within each upazilla three unions (clusters) were purposefully sampled on the basis of perceived limited access to healthcare and feasible accessibility from BADAS-PCP district headquarters. The six unions (clusters) in each district (stratum) were randomly allocated to either intervention or control for the previous maternal and neonatal health intervention and the same allocation remained in place for the current study.

\section{The women's groups intervention}

The intervention involved 162 women's groups that had previously focused on maternal and neonatal health issues as part of the earlier cluster-randomised trial (2005-2007). ${ }^{20}$ These groups met on a monthly basis since 2005. Between 2005 and 2009 , the groups discussed maternal and neonatal health issues. From 2010, they proceeded through a participatory learning and action cycle focusing on health issues relating to children under 5 years of age. This study is an evaluation of that child health focused intervention (figure 2).

A paid female facilitator, who was a local woman of reproductive age with secondary education, led the groups. Each of nine facilitators was responsible for 18 groups. The facilitators received approximately 1 week's training that covered participatory modes of communication, an overview of the country's under-5 health problems, the women groups' community facilitation manual and the use of a pictorial flip chart to

Figure 1 Study location.

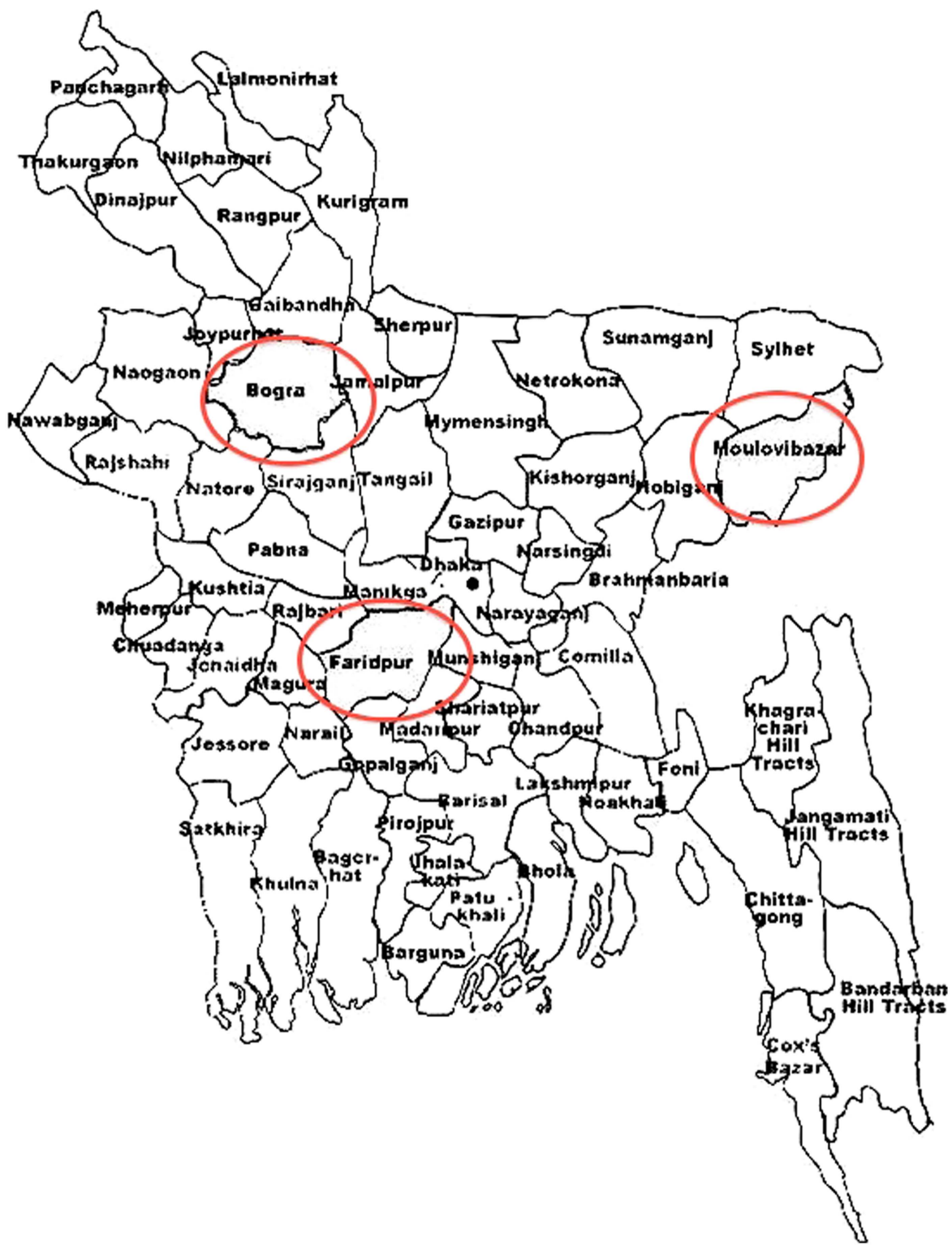


Figure 2 Study flow chart and timeline.

communicate key health messages. The role of the facilitator was to activate and strengthen groups, support them in identifying and prioritising under-5 health problems (phase 1), help identify possible strategies (phase 2), and support the planning, implementation (phase 3 ) and monitoring of the strategies led by the women's group members (phase 4; box 1). Locally recruited supervisors supported facilitators in preparing for meetings and liaising with community leaders and government and non-governmental healthcare providers. The groups discussed a range of under-5 health issues including breast feeding, undernutrition, vitamin A supplementation, immunisation, danger signs, common childhood illnesses and accidents and injuries.

Women were eligible to become members of the women's groups if they were 15-49 years of age and resided in the intervention areas. Women could enter the women's groups at any time during the study period and all members of the community, including men, were welcome to attend meetings in a more passive role. Community meetings were held at the end of phase 2 to engage the wider community in the development and implementation of the women groups' strategies.

Control and intervention clusters all received health services strengthening initiatives throughout the project. These initiatives focused on technical support and training to frontline health workers, the provision of weighing scales and sphygmomanometers to 44 community clinics, and facilitation of links between community clinic committees, union council health committees, upazilla health advisory committees and upazilla health and family planning coordination meetings. These initiatives were intended to strengthen supply-side capacity to respond to community health needs.

\section{Study design}

A quasi-experimental controlled before-and-after study was used to assess the impact of the women's group intervention on child health indicators. Preintervention and postintervention crosssectional surveys were conducted with mothers of children under 5 years using a structured questionnaire. The questionnaire was based in part on questions from demographic and health surveys, ${ }^{22}$ the IMCI household survey, ${ }^{23}$ and infant and young child feeding guidelines ${ }^{24}$ and was pilot tested in the study areas before use. Data were collected on the mother's socioeconomic indicators and knowledge and practices of key indicators and determinants of child health, including breast feeding, complementary feeding and nutrition, immunisation, preventive home care practices, selfreported morbidity and healthcare use for childhood illnesses. A team of 36 data collectors with extensive experience of conducting surveys in the study areas received 3 days of training on the preintervention and postintervention surveys before collecting data in the field. The data collectors were employed by BADAS-PCP and had no role in the implementation of the intervention.

Women's groups are typically comprised of core, 'active' members and other attendees. Active members commit to arrange meetings, take on responsibilities and lead in the implementation of strategies. Attendees take a more passive role in group activities. Eligible study participants were women who permanently resided in the study areas and had a child aged between 29 days and 5 years and, in intervention areas, were active members of a women's group. Women's group registers maintained by group facilitators at every meeting provided the sample list of all actively involved members with children under 5 years of age and efforts were made to interview all eligible women. 
Box 1 Women's groups' meeting plan. Each meeting

follows a standard structure of problem description and generation of ideas to reach conclusions on how to solve or prevent these problems

Phase 1: Identify and prioritise child health problems Meeting 01 Introduction

Meeting 02 Identify child health problems

Meeting 03 Nutrition

Meeting 04 Vitamin A and malnutrition

Meeting 05 Immunisation and danger sign

Meeting 06 Diarrhoea

Meeting 07 Coughs or colds and pneumonia

Meeting 08 Measles

Meeting 09 Other common childhood illnesses

(fever; worms)

Meeting 10 Accidents and injuries

Meeting 11 Plan community visit

Meeting 12 Share community view on child health problems prioritised

Phase 2: Plan strategies

Meeting 13 Plan strategies

Meeting 14 Plan community visit

Meeting 15 Share community views on strategies

Meeting 16 Plan community meeting

Meeting 17 Community meeting

Phase 3: Strategy implementation

Meeting 18 Develop action plan to implement strategies

Meeting 19 Implement strategies

Phase 4: Assess impact

Meeting 21 Review progress on strategy implementation

A register of all births in the study areas maintained by BADAS-PCP since 2005 was used as a sampling frame for the baseline survey in control areas. A random sample was selected from control areas such that the sample size in intervention and control unions was equal within each district. Control areas were oversampled by $20 \%$ to allow for possibly higher refusal rates.

All women interviewed in the presurvey and still meeting the inclusion criteria were included in the postintervention survey. All newly eligible women in the intervention clusters (ie, active women's group member with child under 5 years) were also included in the postintervention survey and an equal number of new participants was sampled from control clusters to maintain comparability.

On the basis of an estimated sample size of approximately 2150 participants in 18 clusters, estimates of baseline levels for a range of outcomes and intracluster correlation coefficient estimates derived from the 2007 Bangladesh Demographic and Health Survey (BDHS), we predicted that our sample would give us between $70 \%$ and $80 \%$ power to detect differences of at least $15 \%$ in most outcomes with $95 \%$ confidence. ${ }^{25} 26$

Interviews were conducted with respondents in their homes. Approximately $10 \%$ of questions from $10 \%$ of all completed questionnaires were crosschecked through a reinterview by field supervisors. Completed questionnaires were checked for completeness and consistency in the district offices before being sent for data entry in the project's Dhaka office. Further checking of the data for quality and completeness took place by the surveillance and data managers in Dhaka and any errors or omissions identified were referred back to the field for verification.

\section{Process evaluation}

Detailed quantitative and qualitative process evaluation information was collected to document the intervention implementation, exposure to and participation in the women's group intervention, and receipt of the intervention by the target population. Structured forms were used by group facilitators to prospectively capture information on attendance at women's group meetings, content and duration of the meetings and strategies implemented.

\section{Statistical analysis}

Difference-in-difference (DID) analysis was used to estimate intervention effects, adjusting for potential differences at baseline. ${ }^{27} 28$ The DID estimator is defined as the difference in the average outcome in the intervention group before and after the intervention minus the difference in the average outcome in the control group before and after the intervention. ${ }^{28}$ For example, if prevalence of disease X was $20 \%$ in intervention clusters and $10 \%$ in control clusters at baseline, and changed to $15 \%$ in intervention clusters and $8 \%$ in control clusters, the absolute change that may be attributed to the intervention is $3 \%$ (ie, $(20-15)-(10-8)=3$ ). This was done in Stata V.12.1 using linear random-effects regression with an interaction term between the study arm and study period (preintervention or postintervention).

\section{Ethical approval}

Ethical approval was obtained from the ethics committees of BADAS, Dhaka and the Great Ormond Street Hospital and Institute of Child Health (GOSH-ICH), London. Women who chose to participate in the study gave verbal consent and were free to decline an interview at any time.

\section{Role of funding source}

The sponsors of the study had no role in the study design, data collection, data analysis, data interpretation or writing of the report. All authors had access to all the data in the study.

\section{RESULTS}

\section{Process evaluation}

In April 2010, 162 women's groups started a cycle of 21 monthly meetings that focused on under-5 children's health. Owing to flooding disruptions, all groups took longer than expected to complete the cycle of 21 meetings, with 26 groups finishing in January 2012 and the remaining 136 finishing in February 2012. In a total population of 229195 people in the nine clusters, 162 women's groups provided coverage of one group per 1414 population. We know from the 2007 women's group trial that $2363(9 \%)$ women of reproductive age in the intervention areas $(n=27614)$ were group members. ${ }^{20}$

A total of 51755 individuals participated in the women's group meetings, $2 \%$ of which were men. The average number of women's group participants per meeting was 19 (range 13-28) and was relatively stable throughout the study period. Intensity of exposure to the intervention among the women's group members during the intervention period (2010-2011) was estimated at $70 \%$, that is, an average of 14 out of 20 meetings were attended.

A total of 157 community meetings were organised by women's groups between October and December 2011 to engage the wider community with the development and implementation of women's group's strategies. Not including women's 
group members, a total of 15272 community members participated in these community meetings and $32 \%$ of participants were men. Strategies discussed and implemented during the community meetings included awareness raising (especially of breast feeding practices), emergency funds, emergency transport and linking women's groups with health services.

\section{Survey response rates}

The preintervention survey was completed for 1897 women926 out of the targeted 1075 women in intervention areas and 971 out of the targeted 1191 women in control areas. This represents a response rate of $86 \%$ in intervention areas and $82 \%$ in control areas. The postintervention survey was completed for 2270 women-1082 out of 1546 in intervention areas and 1188 out of the targeted 1627 in control areas. This represents a response rate of $70 \%$ and $73 \%$, respectively. The main reasons for failure to reinterview in control and intervention areas were migration out of the study area, respondent not being at home at the time of data collection and, in some instances, the respondent being deemed ineligible for inclusion at the point of data collection.

Table 1 Respondents' socioeconomic characteristics before and after the intervention

\begin{tabular}{|c|c|c|c|c|}
\hline & \multicolumn{2}{|c|}{$\begin{array}{l}\text { Preintervention } \\
\text { survey } \\
\text { March-April } 2010\end{array}$} & \multicolumn{2}{|c|}{$\begin{array}{l}\text { Postintervention } \\
\text { survey } \\
\text { October-November } \\
2011\end{array}$} \\
\hline & Control & Intervention & Control & Intervention \\
\hline Respondents & 971 & 926 & 1188 & 1082 \\
\hline Total & 1897 & & 2270 & \\
\hline $\begin{array}{l}\text { Number of under-5 } \\
\text { children }\end{array}$ & 1214 & 1095 & 1567 & 1370 \\
\hline Twins (\%) & 2.3 & 2.8 & 1.2 & 1.8 \\
\hline Males (\%) & 52.9 & 53.1 & 51.4 & 52.7 \\
\hline \multicolumn{5}{|l|}{ Child age (months) (\%) } \\
\hline$\leq 6$ & 9.0 & 10.5 & 4.0 & 6.7 \\
\hline $7-12$ & 8.4 & 8.0 & 7.3 & 9.1 \\
\hline $13-18$ & 10.9 & 10.3 & 6.8 & 8.6 \\
\hline$>18$ & 71.7 & 71.3 & 82.0 & 75.6 \\
\hline Mean child age & 30.5 & 31.0 & 34.7 & 32.1 \\
\hline \multicolumn{5}{|l|}{ Age (years) (\%) } \\
\hline$\leq 19$ & 3.9 & 6.2 & 2.7 & 4.2 \\
\hline $20-24$ & 32.6 & 30.0 & 28.8 & 29.7 \\
\hline $25-29$ & 33.3 & 34.3 & 34.5 & 34.0 \\
\hline $30-34$ & 18.5 & 19.7 & 20.5 & 20.2 \\
\hline$\geq 35$ & 11.8 & 9.7 & 13.5 & 11.8 \\
\hline Mean maternal age & 27.0 & 26.9 & 27.8 & 27.2 \\
\hline \multicolumn{5}{|l|}{ Religion (\%) } \\
\hline Islam & 90.9 & 88.5 & 90.3 & 89.4 \\
\hline \multicolumn{5}{|l|}{ Education (\%) } \\
\hline $\begin{array}{l}\text { None or less than } \\
\text { a year }\end{array}$ & 29.9 & 29.9 & 24.6 & 25.8 \\
\hline Primary & 30.7 & 38.2 & 30.7 & 41.2 \\
\hline Secondary and higher & 39.4 & 32.0 & 44.6 & 33.0 \\
\hline \multicolumn{5}{|l|}{ Literacy (\%) } \\
\hline $\begin{array}{l}\text { Can read (easily or with } \\
\text { difficulty) }\end{array}$ & 66.3 & 65.0 & 72.0 & 69.1 \\
\hline \multicolumn{5}{|l|}{ Economic status } \\
\hline $\begin{array}{l}\text { Mean number of assets } \\
\text { owned per household }\end{array}$ & 6.4 & 5.9 & 6.7 & 6.3 \\
\hline
\end{tabular}

Survey sample and baseline differences

DID analysis compared the preintervention and postintervention control and intervention samples. Results showed no significant differences in changes in socioeconomic characteristics between survey samples and time points (table 1). In other words, there were no significant changes in measured background socioeconomic factors that might account for changes observed in our outcome measures.

With the exception of care seeking, we observed relatively higher frequencies in most outcomes in intervention areas compared with control areas before the start of the child health women's groups' intervention (table 2).

\section{Impact evaluation}

Table 2 summarises the estimates from random-effects regression DID analysis. DID estimates for mothers' knowledge indicators are positive and statistically significant, which indicates that the mother's knowledge of disease prevention, danger signs and hand washing with soap before food preparations and child feeding, oral rehydration solution preparation and exclusive breast feeding improved significantly among the women's group members compared with women in control areas. Women's group members exclusively breast fed their children for approximately 38 days longer than women in control areas. The proportion of children who were exclusively breast fed for 6 months was approximately $15 \%$ higher in intervention areas compared with control areas.

Fewer reports of illness during the 2 weeks preceding the interview were recorded in intervention areas compared with control areas. Improved care-seeking practices for ill children in intervention and control areas were observed at end line relative to baseline, but changes were not statistically significant. Improvements in under-5 minimum dietary diversity were greater in control areas than in intervention areas and the observed improvements in immunisation coverage were not statistically significant.

\section{DISCUSSION}

This formative evaluation shows that participation in a child health focused women's group intervention can improve a range of knowledge, behaviours and under-5 health outcomes. Women who participated in the intervention had improved knowledge of hygienic practices, breast feeding and diarrhoea treatment, and their children were more likely to be exclusively breast fed for longer. Children of women exposed to the intervention had fewer and shorter illness episodes compared with children in control areas. These findings relate specifically to women who participated in the intervention and are a proof-of-principle demonstration of the potential of women's groups to address a wide range of health issues in resource-poor settings, beyond that of maternal and neonatal health, as has been demonstrated previously. ${ }^{16-19}$ That women's groups' interventions are community-led, low-cost and may be implemented independent of the quality of healthcare systems enhances their suitability in settings where implementation of interventions with important community components, such as IMCI initiatives, are hindered by limited health system resources and community health worker capacity. ${ }^{13} 29-31$

It is important to note that some outcomes at baseline in intervention areas were notably higher compared with those in control areas. Possibly, women's group members were previously involved in a similar intervention focusing on neonatal and maternal health, which discussed some overlapping themes with the current child health intervention, such as breast feeding practices. The DID analytical approach attempts to account for these differences when estimating the impact of the intervention. However, such analysis is based on the assumption that, in 
Table 2 DID analysis of the impact of the women's groups' intervention on child health indicators

\begin{tabular}{|c|c|c|c|c|c|c|c|}
\hline \multirow[b]{2}{*}{ Outcomes } & \multicolumn{2}{|c|}{ Control } & \multicolumn{2}{|c|}{ Intervention } & \multirow[b]{2}{*}{ DID estimate } & \multirow[b]{2}{*}{$95 \% \mathrm{Cl}$} & \multirow[b]{2}{*}{$\mathrm{p}$ Value } \\
\hline & Pre & Post & Pre & Post & & & \\
\hline \multicolumn{8}{|l|}{ Mother's under- 5 health-related knowledge } \\
\hline Total $n$ & 971 & 1188 & 926 & 1082 & & & \\
\hline$\geq 3$ ways to prevent diarrhoea (\%) & 14.1 & 40.6 & 41.1 & 94.5 & 26.7 & 22.0 to 31.5 & $<0.001$ \\
\hline$\geq 3$ ways to prevent worms (\%) & 10.4 & 2.1 & 19.4 & 88.2 & 57.1 & 52.8 to 61.4 & $<0.001$ \\
\hline Knowledge of $\geq 3$ danger signs (\%) & 5.8 & 16.7 & 28.9 & 73.0 & 33.2 & 28.7 to 37.8 & $<0.001$ \\
\hline Hand washing with soap before food preparations (\%) & 12.1 & 6.5 & 19.5 & 28.0 & 14.3 & 10.1 to 18.6 & $<0.001$ \\
\hline Hand washing with soap before feeding child (\%) & 24.5 & 20.6 & 29.8 & 58.1 & 32.0 & 26.9 to 37.2 & $<0.001$ \\
\hline Appropriate knowledge on exclusive breast feeding* (\%) & 53.7 & 67.5 & 67.3 & 93.5 & 12.4 & 7.2 to 17.6 & $<0.001$ \\
\hline Correct knowledge of ORS preparationt (\%) & 47.4 & 57.2 & 58.2 & 90.7 & 22.9 & 17.4 to 28.4 & $<0.001$ \\
\hline \multicolumn{8}{|l|}{ Under-5 health-related outcomes } \\
\hline Total $n$ & 1214 & 1567 & 1095 & 1370 & & & \\
\hline $\begin{array}{l}\text { Exclusive breast feeding for at least } 6 \text { months } \\
\text { (children aged } \geq 6 \text { and } \leq 20 \text { months only) (\%) } \neq\end{array}$ & 43.0 & 50.6 & 58.7 & 81.4 & 15.3 & 4.2 to 26.5 & 0.007 \\
\hline $\begin{array}{l}\text { Mean duration of exclusive breast feeding } \\
\text { (children aged } \leq 20 \text { months and breast feeding terminated) (days)§ }\end{array}$ & 93.7 & 109.8 & 112.5 & 166.4 & 37.9 & 17.4 to 58.3 & $<0.001$ \\
\hline Child illness during the 2 weeks preceding the survey (\%) & 25.2 & 26.7 & 27.2 & 22.8 & -5.9 & -10.6 to -1.2 & 0.013 \\
\hline Reported diarrhoea during the 2 weeks preceding the survey (\%) & 7.1 & 1.7 & 7.6 & 2.0 & -0.1 & -2.3 to 2.0 & 0.910 \\
\hline Reported ARI during the 2 weeks preceding the survey $\uparrow(\%)$ & 8.0 & 13.7 & 14.5 & 8.0 & -12.2 & -15.6 to -8.8 & $<0.001$ \\
\hline Reported fever during the 2 weeks preceding the survey (\%) & 21.6 & 27.5 & 24.0 & 19.3 & -10.5 & -15.1 to -6.0 & $<0.001$ \\
\hline Mean duration of child illness among those reporting any illness (days) & 5.3 & 3.9 & 5.8 & 3.6 & -0.8 & -1.4 to -0.1 & 0.017 \\
\hline $\begin{array}{l}\text { Under- } 5 \text { reported illness lasting more than } 7 \text { days during the } 2 \text { weeks } \\
\text { preceding the survey (\%) }\end{array}$ & 4.5 & 1.6 & 7.2 & 1.2 & -3.0 & -5.0 to -1.1 & 0.002 \\
\hline $\begin{array}{l}\text { Appropriate care-seeking for children reported ill lasting more than } 7 \text { days } \\
\text { the } 2 \text { weeks preceding the survey** }(\%)\end{array}$ & 44.1 & 82.4 & 27.7 & 88.3 & 22.1 & -6.8 to 51.1 & 0.135 \\
\hline Minimum dietary diversity $+\dagger$ (age $\geq 6$ months and $\leq 23$ months) (\%) & 40.1 & 57.7 & 51.4 & 57.4 & -11.9 & -22.3 to -1.4 & 0.026 \\
\hline Children aged $\geq 12$ and $\leq 23$ months received full immunisation schedule & 82.4 & 82.8 & 72.9 & 84.6 & 11.4 & -0.3 to 23.1 & 0.056 \\
\hline
\end{tabular}

*Respondents demonstrated correct knowledge of the optimal duration of exclusive breast feeding, that is, 6 months. Data missing for 64 cases. No association between missing data and study arm.

†Respondents described the correct components, quantities and preparation of ORS.

$\neq$ Children aged $>6$ and $<20$ months=281 (control, pre); 239 (intervention, pre); 270 (control, post); 300 (intervention, post). Sixteen cases had missing data on exclusive breast feeding duration. No association between missing data and study arm.

$\S$ Children aged $<20$ months and breast feeding terminated=322 (control, pre); 289 (intervention, pre); 282 (control, post); 287 (intervention, post). Thirty-seven eligible cases had missing data on breast feeding duration. No association between missing data and study arm.

TARI in this definition includes reported coughs.

** Respondents sought care from a health facility.

t+Minimum dietary diversity score: proportion of children 6-23 months of age who receive food from four or more food groups. Children aged 6-23 months=333 (control, pre); 286

(intervention, pre); 368 (control, post); 387 (intervention, post).

$A R I=a c u t e$ respiratory infection; DID, difference-in-difference estimate; ORS, oral rehydration solution.

the absence of intervention, changes would have been similar in intervention and control arms. This assumption may be unreasonable for outcomes where the intervention areas differ markedly from control areas at baseline, as the baseline prevalence may be associated with the change, so for such outcomes the findings must be interpreted with some caution.

Nonetheless, our study findings in relation to breast feeding are particularly encouraging. Breast feeding has a direct link to child development and nutritional status. ${ }^{2}$ Although breast feeding is almost universal in Bangladesh, increasing the duration of exclusive breast feeding is imperative to improve child survival and improved breast feeding practices are more likely to occur when mothers perceive them as beneficial. ${ }^{32}$ Indeed, the intervention provided intensive messages on the importance and benefits of exclusive breast feeding. These messages were repeated in most women's group meetings, and women's groups recognised that improvements in child feeding practices can be achieved through feasible strategies negotiated with pregnant and breast feeding women. These strategies were communicated at the community level through community meetings organised by women's groups and through simple and clear messages that encouraged women to exclusively breast feed, which included repeated reminders of benefits and the promotion of societal support of lactating women during both community and subsequent women's groups meetings. Furthermore, given that actions by family members can either build or challenge a mother's confidence and her ability to adopt new practices, ${ }^{33}$ participation in women's groups was open to community members to foster familial support.

Knowledge of methods to prevent diarrhoea and worms and the home care and management of diarrhoea improved in intervention areas relative to control areas. We also observed significant decreases in reported ARI and fever among children in intervention areas, and overall we observed significant decreases in the number of children whose mother reported an illness in the 2 weeks preceding the survey. Improved knowledge of danger signs and better ability to recognise ill health may have resulted in reduced false-positive reports in intervention areas thus, caution is needed in the interpretation of these subjective measures of morbidity. Nevertheless, significant improvements in care-seeking behaviours for children with ARI and fever were observed (results not shown), which may support the finding of reduced mean illness duration and reduced illness lasting more than a week in intervention areas.

Baseline data on care seeking showed better care seeking for ill children among respondents from control areas compared with 
intervention areas. The reasons for this are not well understood, but we know from anecdotal evidence and field observations that control areas may enjoy better access to health facilities than intervention areas. Our study did not collect data on indicators of the discrepancies in the availability and utilisation of services for different subgroups in the population. Nor did we explore woman's perceptions of care and quality of care, which may have provided a better understanding of the context of care seeking and a clearer indication of strategies on how to improve care seeking.

Minimum dietary diversity for children aged 6-23 months improved in intervention and control areas, but the gains were greater in control areas. It is unlikely that the women's group intervention hindered gains in dietary diversity in intervention areas and the observed differences more likely to reflect the underlying contextual differences between study arms that may not be readily amenable to change through participatory learning and action through women's groups over a relatively short period. Absence of any evidence for a positive effect of the women's group intervention may reflect a need for more focused discussions on nutrition than those offered during a single meeting in our intervention. Further qualitative work on community attitudes to food consumption and surveys of food availability and security might provide a better understanding of how community mobilisation interventions might be better able to address nutrition.

No significant impact on immunisation was observed, although coverage rates were already high and there were larger increases in intervention areas than in control areas. Our immunisation data on vaccination coverage are consistent with those reported at the national level, where there has been a notable improvement in recent years. ${ }^{9}$ It is unclear whether community mobilisation through women's groups has a role to play in improving immunisation; however, it is most likely that the intervention would need to tackle more nuanced issues of why parents do not vaccinate their children such as addressing cultural and economic barriers to vaccination.

\section{CONCLUSION}

Community mobilisation through participatory women's groups can be successfully adapted to address health knowledge and practice in relation to child health leading to improvements in a number of indicators and behaviours, including the duration of exclusive breast feeding. The ability to achieve a similar impact at the community level and among women and children beyond those who directly engage with the intervention, as has been demonstrated for maternal and neonatal health, remains to be tested.

\section{What is already known on this subject}

- Strategies to tackle under-5 child health have largely focused on care and practices before and during the neonatal period, mostly overlooking practices that may impact the health of children during the postneonatal period.

- Studies of knowledge and practice related to the health of under-5s have been generally fixed on single themes such as prevention and management of diarrhoea, acute respiratory infections, etc. Many of these studies depend mainly on the strength of the health system responsible for their implementation. Health system constraints and capacity for scale-up and follow-up after training can hinder the expansion of high-quality interventions at the national level.

- Few studies investigate mothers' knowledge and practices on a range of integrated issues related to under- 5 child health at the community level.

\section{What this study adds}

- Significant improvements were observed in intervention areas with respect to exclusive breast feeding and mean duration of breast feeding, under-5 health-related knowledge such as disease prevention and management, mothers' knowledge of danger signs and hand washing at critical times.

- The results highlight that community mobilisation through participatory women groups is feasible and can be successfully adapted to address under- 5 health-related knowledge and practices in rural settings.

- Women's groups are community-led, low-cost and not reliant on the quality of healthcare systems; this may enhance their suitability in settings where implementation of interventions with important community components are hindered by limited health system resources and community health worker capacity.

Acknowledgements The women's groups' intervention is funded by the Big Lottery Fund International Strategic Grant and supported by a Wellcome Trust Strategic Award (085417ma/Z/08/Z). The authors would also like to acknowledge contributions on the data analysis methods of this paper from Nadine Seward and David Osrin.

Contributors EF, TAJH and LY designed the study protocol and questionnaire, and devised methods to estimate the impact. All authors contributed to the drafting and revision of the manuscript. EF and $L Y$ prepared the first draft of the manuscript and conducted data analysis. BH provided process data. SS, MH and JB provided and monitored data capture and management. AP and ACop reviewed the results and contributed to the interpretation of data. All authors participated in the interpretation of results and revisions of the manuscript. All authors read and approved the final manuscript.

Funding The Big Lottery Fund (UK).

\section{Competing interests None.}

Ethics approval Ethical approval was obtained from the ethics committees of the Diabetic Association of Bangladesh (BADAS), Dhaka and the Great Ormond Street Hospital and Institute of Child Health (GOSH-ICH), London.

Provenance and peer review Not commissioned; externally peer reviewed.

Open Access This is an Open Access article distributed in accordance with the Creative Commons Attribution Non Commercial (CC BY-NC 4.0) license, which permits others to distribute, remix, adapt, build upon this work non-commercially, and license their derivative works on different terms, provided the original work is properly cited and the use is non-commercial. See: http://creativecommons.org/ licenses/by-nc/4.0/

\section{REFERENCES}

1 UNICEF, WHO, World Bank. Levels and trends in child mortality report 2013. Estimates developed by the UN Inter-agency group for child mortality estimation. http://www.childinfo.org/files/Child_Mortality_Report_2013.pdf

2 UNICEF. Committing to child survival: a promise renewed. 2012. http://www.unicef org/videoaudio/PDFs/APR_Progress_Report_2012_final.pdf

3 Darmstadt GL, Bhutta ZA, Cousens S, et al. Evidence-based, cost-effective interventions: how many newborn babies can we save? Lancet 2005;365:977-88

4 UNICEF, WHO. Accountability for maternal, newborn and child survival: the 2013 update. http://countdown2015mnch.org/documents/2013Report/Countdown_ 2013-Update_noprofiles.pdf

5 WHO. Community-based strategies for breastfeeding promotion and support in developing countries. 2003. http://www.who.int/maternal_child_adolescent/ documents/9241591218/en/

6 UNICEF, WHO. Diarrhea: why children are still dying and what can be done? 2009 http://www.who.int/maternal_child_adolescent/documents/9789241598415/en/

7 Thakur N, Kumar A. A study on delivery and newborn care practices in urban slums of Ganda community. Am J Phys Anthropol 2012;8:33-8.

8 Saha KK, Frongillo EA, Alam DS, et al. Appropriate infant feeding practices result in better growth of infants and young children in rural Bangladesh. Am J Clin Nutr 2008;87:1852-9. 
9 National Institute of Population Research and Training (NIPORT), Mitra and Associates, Macro International: Bangladesh Demographic and Health Survey 2011. In Dhaka, Bangladesh and Calverton. Maryland USA: National Institute of Population Research and Training, Mitra and Associates, and Macro International.

10 National Institute of Population Research and Training (NIPORT), Mitra and Associates, Macro International: Bangladesh Demographic and Health Survey 2004. In Dhaka, Bangladesh and Calverton. Maryland USA: National Institute of Population Research and Training, Mitra and Associates, and Macro International.

11 Sayem AM, Nury AT, Hossain MD. Achieving the millennium development goal for under-five mortality in Bangladesh: current status and lessons for issues and challenges for further improvements. J Health Popul Nutr 2011;2:92-102.

12 Goodburn EA, Chowdhury M, Gazi R, et al. Training traditional birth attendants in clean delivery does not prevent postpartum infection. Health Policy Plan 2000;15:394-9.

13 El-Arifeen S, Hoque E, Akter T, et al. Effect of the Integrated Management of Childhood Illness strategy on childhood mortality and nutrition in a rural area in Bangladesh: a cluster randomised trial. Lancet 2009;374:393-403.

14 Rahman SM, Ali NA, Jennings $L$, et al. Factors affecting recruitment and retention of community health workers in a newborn care intervention in Bangladesh. Hum Resour Health 2010;8:12.

15 Bryce J, Victoria CG, Habicht J-P, et al. Programmatic pathways to child survival: results of a multi-country evaluation of Integrated Management of Childhood Illness. Health Policy Plan 2005;20:5-17.

16 Manandhar DS, Osrin D, Shrestha BP, et al. Effect of a participatory intervention with women's groups on birth outcomes in Nepal: cluster-randomised controlled trial. Lancet 2004;364:970-9.

17 Tripathy P, Nair N, Barnett $\mathrm{S}$, et al. Effect of a participatory intervention with women's groups on birth outcomes and maternal depression in Jharkhand and Orissa, India: a cluster-randomised controlled trial. Lancet 2010;375:1182-92.

18 Fottrell E, Azad K, Kuddus A, et al. The impact of increased coverage of participatory women's groups on neonatal mortality in Bangladesh: a cluster randomized trial. JAMA Pediatr 2013;167:816-25.

19 Prost A, Colbourn T, Seward N, et al. Women's groups practising participatory learning and action to improve maternal and newborn health in low-resource settings: a systematic review and meta-analysis. Lancet 2013;381:1736-46.

20 Azad K, Barnett S, Banerjee B, et al. Effect of scaling up women's groups on birth outcomes in three rural districts in Bangladesh: a cluster-randomised controlled trial. Lancet 2010;375:1193-202.
21 Houweling T, Azad K, Younes L, et al. The effect of participatory women's groups on birth outcomes in Bangladesh: does coverage matter? Study protocol for a randomised control trial. Trials 2011;12:208.

22 National Institute of Population Research and Training (NIPORT), Mitra and Associates, Macro International: Bangladesh Demographic and Health Survey 2007. Dhaka, Bangladesh and Calverton Maryland USA: National Institute of Population Research and Training, Mitra and Associates, and Macro International, 2009.

23 UNICEF. Child health/ IMCI: household baseline survey. 1999. http://www.unicef. org/health/files/health_generic.pdf

24 FANTA.2, WHO, UNICEF, IFPRI, USAID. Indicators for Assessing Infant and Young Child Feeding Practices. PART 1 DEFINITION. WHO Library Cataloguing-in-Publication Data. 2008.

25 Hayes R, Bennett S. Simple sample size calculation for cluster-randomised trials. Int $J$ Epidemiol 1999;28:319-26.

26 Hayes R, Moulton Z. Chapter 7: sample size. In: Cluster randomised trials. Chapman \& Hall/CRC Interdisciplinary Statistics Series, 2009:105-29.

27 Besley T, Case A. Unnatural experiments? Estimating the incidence of endogenous policies. Econ J 2000;110:672-94.

28 Branas CC, Cheney RA, MacDonald JM, et al. A difference-in-differences analysis of health, safety, and greening vacant urban space. Am J Epidemiol 2011;11:1296-306

29 Pariyo GW, Gouws E, Bryce J, et al. Improving facility-based care for sick children in Uganada: training is not enough. Health Policy Plan 2005;20:58-68.

30 Schellenberg JRMA, Adam T, Mshinda $\mathrm{H}$, et al. Effectiveness and cost of facility-based Integrated Management of Childhood IIness (IMCI) in Tanzania. Lancet 2004;364:1583-94.

31 El-Arifeen S, Blum LS, Hoque DME, et al. Integrated Management of Childhood Illness (IMCI) in Bangladesh: early findings from a cluster-randomised study. Lancet 2004;364:1595-602.

32 Mihrshahi S, Ichikawa N, Shuaib M, et al. Prevalence of exclusive breastfeeding in Bangladesh and its association with diarrhoea and acute respiratory infection: results of the multiple indicator cluster survey 2003. J Health Popul Nutr 2007;25:195-204.

33 Hadi A. Management of acute respiratory infections by community health volunteers: experience of Bangladesh Rural Advancement Committee (BRAC). Bull World Health Organ 2003;81:183-9. 